\title{
LOS NIÑOS ERRANTES DEL CINE IRANÍ DEL MITO A LA HISTORIA
}

Farshad Zahedi1: Universidad Carlos III de Madrid. España farshad.zahedi@uc3m.es

\section{RESUMEN}

Este estudio es un esfuerzo por analizar la imagen de los niños y adolescentes en el cine iraní y su relación con la imagen de infancia que existe en la mitología y la literatura persa. El niño sabio aparece en los momentos de crisis, cuando la lógica de los adultos basada en la experiencia y control patriarcal es incapaz de resolver un problema social y todas las líneas de comunicación y diálogo entre el pueblo y los opositores -o bien como una amenaza externa o bien como un tirano gobernante- han llegado a un callejón sin salida. En este momento crucial la inteligencia no contaminada por la lógica del beneficio mediante una estrategia dotada por un alto grado de flexibilidad salva a la identidad colectiva de la crisis y resuelve el problema. En el cine, este mito aparece en un momento crítico del contacto de los iraníes con la modernidad y se convierte en el protagonista de una serie de películas en un determinado contexto histórico-social. La imagen del niño errante construye una perfecta relación microcósmica con las realidades sociales en una imagen alegórica de una sociedad en el pleno proceso de cambio del sistema de valores, y por lo tanto en una profunda crisis de identidad.

PALABRAS CLAVE: Cine iraní- Niños errantes- Mitología persa- Crisis de identidadEspacio educativo.

\section{THE WANDERING CHILDREN OF IRANIAN CINEMA FROM MYTH TO HISTORY}

\begin{abstract}
This study is an effort to analyze the image of children and adolescents in Iranian cinema, and its relationship to the image of the childhood that exists in Persian mythology and literature. The wise child appears in the times of crisis, when the logic

\footnotetext{
${ }^{1}$ Autor correspondiente

Farshad Zahedi: Doctor en Historia del Cine por la Universidad Autónoma de Madrid. Profesor Ayudante del Departamento de Periodismo y Comunicación Audiovisual de la Universidad Carlos III de Madrid. Madrid, España

Correo: farshad.zahedi@uc3m.es
} 
of the elderly, based on patriarchal experience and control, is unable to solve a social problem, and all lines of communication and dialogue between the people and opponents - either as an external threat or as a tyrant ruler-, have reached an impasse. At this crucial moment, the wise child's particular logic save the people and solve the problem through the intelligence which is not contaminated by the logic of benefit, and through a strategy that is only possible by its high flexibility. In cinema, this myth appears at a critical moment of Iranians contact with the modernity, and becomes the protagonist in a number of Iranian movies in a certain social-historical context. The educational space, moving this character forward, builds a perfect microcosmic relationship with social reality and sometimes turns the text into an allegorical image of a society which is changing value system, and thus in a deep identity crisis.

KEY WORDS: Iranian Cinema - Wondering Children - Persian Mythology Identity Crisis - Educational Space.

\section{INTRODUCCIÓN}

En los años ochenta y noventa proliferan las pantallas del cine iraní por la imagen de los niños y adolescentes que tienen que desempeñar un problema en una especie de viaje iniciático. Fue Abbas Kiarostami el más reconocido en los festivales internacionales por esta imagen, y fue él a quién le ha sido atribuida una determinada escuela cinematográfica en la que los niños y adolescentes tienen un papel central. De manera que para los cinéfilos militantes, a mediados de los noventa, los niños errantes del cine iraní se convierten incluso como un signo de autenticidad de los filmes iraníes que llegaban a Occidente.

Para encontrar razones de la abundancia de esta imagen en estas dos décadas, algunos historiadores han observado a las políticas culturales del Estado iraní a partir de la Revolución de 1979, según las cuales había limitaciones importantes en enseñar relaciones intersexuales de los personajes, así como sus tendencias ideológicas más allá de de lo que marcaba la "batalla dialéctica" de los revolucionarios con el Occidente. Por tanto no era de extrañar la aparición de una figura asexuada y según la lógica freudiana "ideológicamente libre" en el cine iraní, como medida de escape al omnipresente sistema de censura local. Hay un grado de verdad en esta opinión pero no es la única perspectiva por la cual se pueda observa a este fenómeno. El punto de partida de la imagen de la infancia y las referencias reales que le circunscriben vuelven a una década anterior a la Revolución y en concreto en los primeros brotes del nuevo cine iraní en la obra de los directores, entonces jóvenes, formados en las cinematecas y círculos literarios y teatrales.

No es nada gratuito, que dichos cineastas introduzcan la metafórica imagen de la infancia que existe en ocasiones en forma de "niño sabio" en la mitología y en la tradición literaria persa en el cine iraní para construir un nuevo y moderno mito en una circunstancia cultural marcada por la crisis de identidad. Este estudio es un esfuerzo de buscar las raíces culturales de dicha imagen dentro de la mitología persa 
para poder encontrar los elementos estructurales que constituyen la figura del niño errante y le relacionan con el mito de niño sabio que existe en el imaginario colectivo iraní a través de su mitología particular.

\section{METODOLOGÍA}

La metodología de este cometido, es un análisis comparativo entre los niños sabios de la mitología persa y los niños errantes del cine iraní. Los arquetipos que puedan explicar dichas imágenes se encuentran en los primeros textos literarios escritos durante la historia antigua iraní, por lo que buscaremos unos ejemplos que cristalicen de mejor manera la estructura del mito. Así pues algunos ejemplos cinematográficos derivados de esta estructura serán puestos en el punto de simetría con el mito para llegar a una lógica conclusión.

\section{ANÁLISIS Y DISCUSIÓN}

\subsection{El mito de niño sabio}

En la importancia de la educación entre los pueblos que habitaban en el Irán antiguo, algunos recursos griegos y romanos contemporáneos de la época de los Aqueménidas y de los Arsácidas ${ }^{2}$ atestiguan la existencia de una especie de literatura épica-oral que sobre todo fueron consideradas como instrumentos útiles para la transmisión de la sabiduría, códigos morales y valores sociales de los padres e instructores, a los niños y adolescentes (Bahrami, 1999, p.12). Una gran parte de estas historias narradas, se han recopilado a posteriori en los libros de la historia y de la épica, y entre ellos en la gran obra de Ferdowsi: La carta de los reyes (Shahnameh). Asimismo la imagen de infancia aparece con frecuencia en los textos mitológicos persas y constituye uno de los arquetipos culturales al paralelo de la imagen de otros personajes míticos; tales como: Pahlavan (héroes y heroínas, defensores de la nación), reyes (Shahan) y la sabiduría sobrenatural encarnada en las figuras de Amshaspandan (espíritus del bien), Simorgh (el ave mitológico) o Pir (el viejo sabio).

El primer niño sabio, en la mitología persa quizás fuera el propio profeta Zaratushtra, quien ríe al nacer por la inspiración de Bahman ${ }^{3}$ en presencia de los siete brujos del Mal, enviados de Ahriman ${ }^{4}$. La risa de Zaratushtra al nacer, es interpretada por los sacerdotes como una prueba de su consciencia y saber de su propia pureza, cuyo efecto infunde miedo entre los enviados del Mal. El texto Vichitakiha I Zat Sparam $^{5}$ atestigua que Zaratushtra, es poseedor de la razón divina en su espíritu, la

\footnotetext{
2 Como ejemplo podemos apuntar a los textos griegos Cyropaedia de Jenofonte y Historias de Herodoto; y a los textos latinos atribuidos a Plinio y a Dión Casio

${ }_{3}$ El primer creado de la divinidad zoroastriano Ahuramazda, espíritu del Bien, símbolo de la razón, reflexión y la sabiduría divina

${ }^{4}$ El demonio, junto con Ahuramazda son las bases del dualismo zoroastriano

${ }^{5}$ Escrito en siglo III d.C., por el sacerdote zoroastriano de la corte Sasánida, Zat Sparam, es un texto escrito en Pahlavi que recoge episodios de la vida de Zaratushtra en un contexto mitológico. Una traducción del mismo al inglés se encuentra en ANKLESARIA, B.T. (1964), Vichitakiha I Zat - Sparam,
} 
cual le ilumina el camino, dejando atrás diferentes peligros causados por Ahriman. Su estrella es su inteligencia la cual le salva de las amenazas para llegar a la madurez y salvar a su pueblo de la superstición y la irracionalidad de las ciencias oscuras propagadas por Ahriman (Amuzegar y Tafazzali, pp. 43-46).

Para las religiones mazdeistas, la infancia en un sentido ideal, estaba dotada por una razón instintiva divina, la que guiará al individuo al camino del Bien. Esta razón, tan pura de la lógica de beneficio, será profundamente perniciosa para el dominio del Mal. La mitología persa es la escena de un enfrentamiento entre la ciencia del Bien (una razón intuitiva, divina y constructiva) y la ciencia del Mal (una ciencia demoníaca, egocéntrica y destructiva). El Bien vence al Mal, y en ocasiones, el héroe vencedor es un niño que con la ayuda de su razón, salva a sí mismo, a su pueblo e incluso a la misma Razón (Bahrami, 1999, p.15).

En La carta de los reyes hay ejemplos que cristalizan esta idea de la unión entre la inocencia infantil y la sabiduría sobrenatural para formar el niño sabio que tras un viaje iniciático llegaría a la madurez y se salva del mundo irracional de las fuerzas del Mal. El Mal puede reinar en un pueblo cuando sofoca cualquiera manifestación de ésta combinación ideal entre la razón e inocencia ${ }^{6}$. El ejemplo sublime se encuentra en la historia de Bastur el hijo de siete años de edad de Zarir, hermano de Goshtasb, el rey iraní. Cuando los iraníes aceptan la religión zoroastriana, son amenazados por los hunos reinados por Aryasb. Goshtasb para defender a Irán del enemigo, reúne su tropa de soldados y al Pahlavan de los mismos, Zarir. Los hunos matan a Zarir con la ayuda de las trampas de un brujo llamado Biderafsh. La tropa iraní perdiendo a su Pahlavan, pierde la valentía. Goshtasb, convoca a los guerreros más valientes de su ejército pidiendo la venganza de Zarir, pero nadie excepto su hijo Bastur pide el permiso para ir a la guerra. Goshtasb no permite al niño ir al campo de batalla, le considera menor y tampoco quiere perderle igual que a su padre. Bastur clandestinamente entra en el campo de batalla, llega al cuerpo sin vida de su padre y se despide de él, volviendo hacía el rey, salvándose del enemigo. El rey esta vez le permite la vuelta a la guerra. Los hunos buscan remedio de reducir a Bastur a través de la magia y trampas de Biderafsh, quien vuelve al campo montando el propio caballo de Zarir en busca del niño. El caballo reconoce a Bastur, y trae a Biderafsh a su alcance. El espíritu de Zarir inspira al hijo la manera de tirar la flecha con el arco. Bastur mata al brujo. Los iraníes al ver la valentía e inteligencia del niño, cobran la

Bombay; también existe una excelente traducción al persa contemporáneo en BAHAR, Mehrdad (1996) [1375], Payuheshi dar asatir-e Irán [un estudio de la mitología persa], Agah, Teherán.

${ }^{6}$ Un ejemplo brillante puede ser la historia de Zahak el rey que había usurpado el trono real iraní después de años de caos y a quién Ahriman como señal de confianza y aprecio, besa sus hombros. Del lugar del beso nacen dos serpientes las cuales tan sólo se alimentan del cerebro de los más jóvenes. Los mil años de reinado de Zahak, terminan con la rebelión de Fereydun. Véase: FERDOWSI, Abolghasem, HAMIDIAN, Saeid (1388) [2009], Shahnameh [La carta de los reyes], Gatreh, Teherán. Asimismo una de las últimas traducciónes del magistral libro de Ferdowsi en inglés se encuentra en: FERDOWSI, Abolghasem, DAVIS Dick (2004), The Shahnameh: The Persian Book of Kings, Mage Books, Waldorf MD 
valentía con la ayuda de Esfandyar, el hijo de Goshtasb, vencen al enemigo y salvan su señal de identidad. ${ }^{7}$

\subsection{La relación microcósmica con la realidad}

Los ejemplos de la mitología persa aquí expuesto nos ayudan para interpretar una posible infraestructura del mito de niño errante en el cine iraní a través del método que proponía Claude Leví-Strauss (1978, p.8-9), para encontrar el orden tras el aparente desorden de éstas historias míticas. Asimismo para poder llegar al código cultural de estas imágenes, buscamos la manera en que dialogan estos mitos con su contexto histórico. Declara Bahram Beizai (2009. p. 29) que su oficio como escritor y cineasta consiste en fragmentar los mitos para reconstruirlos de nuevo desde la perspectiva de su propia generación. Así pues, y en busca de esta iconografía reconstruida, encontramos a la imagen de la infancia que aparece en la cultura iraní en los momentos de la crisis socio-política durante los setenta, cuando un tratamiento moderno al mito del niño sabio sirve para realizar una representación de las circunstancias sociales en un espacio microcósmico.

La primera imagen de la infancia en cine iraní aparece con la fundación del departamento cinematográfico del Centro para el Desarrollo Intelectual de los Niños y Adolescentes (Kanun-e Parvaresh-e Fekri-ye Kudakan va Noyavanan) en 1969, dónde cooperan unos de los todavía jóvenes directores de un movimiento que posteriormente fue nombrado como sinema-ye motefävet (el cine alternativo): El tio bigotudo (Amu sibilu, Bahram Beizai, 1970) y Pan y callejuela (Nan va kucheh, Abbas Kiarostami, 1970), inauguran este espacio que desde el principio tenía el motivo de producir películas diferentes para los Niños y Adolescentes.

Los niños en el Tío bigotudo encuentran la manera de llegar a la paz con el hombre corpulento y bigotudo, para poder seguir jugando al fútbol en el descampado por delante de su casa. Mientras el cortometraje de Beizai era una muestra de la inquietud de su autor por la violencia cultural subyacente hacía los niños, Pan y callejuela era un perfecto dibujo topográfico del mito de niño sabio: la única manera de salvación a la amenaza del perro salvaje que acecha en el camino del niño protagonista que vuelve a casa con el pan en la mano, es usar la propia inteligencia.

\subsection{Transgresión de la ley paterna}

El chaparron (Ragbar, Bahram Beizai, 1972), es la primera obra en la historia del cine iraní que dedica su argumento al problema de la educación. La trama de la película se desarrolla alrededor de la vida de un profesor recién llegado a un colegio en un barrio

\footnotetext{
7 Según los resultados de la investigación de lingüista francés E. Benveniste, la historia de Bastur, recogida por Ferdowsi en Shahnameh en la época islámica, viene de un texto métrico teatral escrito en Pahlavi en la época de los Arsácidas (248 a.C-209 d.C) como el más antiguo drama iraní reconocido hasta la actualidad: BENVENISTE, Emile (1932), "Le Mémorial de Zarir", Journal Asiatique, vol. CCXX. Así pues una traducción al persa contemporáneo de este texto se encuentra en BAHAR, Mehrdad (1996) [1375], Pajuhesh-i dar asatir-e Iran [Un estudio de la mitología iraní], vol.I-II, Agah, Teherán.
} 
al margen de una ciudad. Hekmati el profesor a su llegada se enfrenta con un sistema educativo marcado por la segregación y malos tratos, propagado no obstante bajo la tutela de una versión convencional de la educación moderna. Este sistema, más que educar sirve para uniformar a los jóvenes, quitarles la capacidad de reflexión y creatividad, y conducirles a un conformismo en un estado absoluto. Hekmati, el nuevo profesor es irreductible a este sistema, y rechaza uno por uno sus ofertas y tentativas, y se resiste contra sus amenazas.

Él, habla de la belleza contraponiendo a la fealdad de la versión oficial, otorgada a una categoría casi ontológica ${ }^{8}$. Hekmati, idealista y soñador, intenta acercarse más a los alumnos, les habla de la creación y de sus propias identidades. Reconstruye la sala arruinada del teatro del colegio como un emblema de un nuevo espacio de comunicación, en que Gazaleh Alizadeh (1992, p. 138) ha visto un símbolo de la herencia cultural, olvidada y arruinada, la que Hekmati pretende renovar para devolverle la vida y creatividad. Sus esfuerzos hacen brotar una nueva consciencia en los niños y sus parientes.

La rebeldía de los niños es una muestra de esta nueva consciencia. Beizai (1992, p. 43) cree que todas rebeldías de los niños y las mujeres, es una protesta al despotismo del sistema androcéntrico. Sin embargo el nuevo saber difundido por Hekmati produce miedo entre los patrones del espacio educativo. El final de la película es cuando, el solitario profesor, tiene que marcharse del colegio y del barrio, dejando atrás a una multitud que le consideraban su héroe salvador.

El colegio en El chaparrón, era un campo de interferencia de las tendencias sociales de su momento; un crucifijo de diferentes identidades. Por una parte una tradición carente de la movilidad que para Beizai (1992, p. 47-56) necesitaba una revisión urgente, y por otro lado una versión local de un orden modernizador basado en la ideología convencional del momento que revestía las tradiciones anquilosadas. En este medio, los niños se quedaban en medio del camino de los dos extremos, y se convertían en los perfectos intermediaros entre los dos bandos dibujados sobre la dicotomía de la ciencia vs Ahriman de la cultura persa: por una parte la inquietud por saber y por otra los agentes de la ideología dominante. El intento de Hekmati, de traspasar la capa superflua de ambas partes, se queda en vano; todavía hay mucha energía social y el esfuerzo del solitario héroe no es suficiente.

La película era una crítica al sistema de educación de su tiempo. No eran pocos los críticos que habían detectado un microcosmos social en el colegio, dónde domina un sistema totalitario ${ }^{9}$. La versión oficial del sistema de educación propagado por el director y los profesores, es aparentemente moderno pero en el fondo no es nada más

\footnotetext{
${ }^{8}$ Véase Dariush Shayegan, “¿Es Teherán una ciudad emblemática?”, Letras Libres, nº68, mayo de 2007. http://www.revistasculturales.com/articulos/91/letras-libres/731/1/-es-teheran-una-ciudademblematica.html. (Consultado en 16 de marzo de 2011)

9 Véase por ejemplo Tahami Neyad, Mohammad (1992), en GUKASIAN, Zaven (ed.), Maymue-ye magalat, Agah, Teherán
} 
que la metamorfosis del antiguo sistema de control. El "Prometeo" solitario cultiva la semilla de la consciencia, contraponiendo al deseo del Padre-Sistema, y de aquí empieza el conflicto.

El idealismo de Hekmati, era un reflejo de la reacción de autor en cuanto a su condición social. Por una parte la sociedad iraní necesitaba un largo tiempo de reflexión para poder asimilar la base del pensamiento moderno, que no se había considerado en ninguno de los programas de la modernización del Estado. Los petrodólares aceleraban este proceso, y cegaban la perspectiva de la producción y la creatividad social. El Estado como el único administrador de la riqueza, ejercía su control en forma absoluta, formando un círculo de fieles como brazos del sistema paternalista y protegidos no obstante por el mismo.

De esta manera, los más marginados eran los más olvidados. La película de Beizai era una reacción a este sistema de control, y Hekmati, el hombre rebelde, se encontraba arrojado en el centro de este mismo sistema, y su anhelo a la verdad le colocaba por delante de la lógica del beneficio de ambos contrincantes: por una parte la gente del barrio, y por otra el director del colegio y del resto de los profesores. Hekmati, tiene que abandonar el barrio. Él, como los héroes de Dostievski, es un admirador de la belleza, y puede transmitir su mensaje a sus alumnos, pero este acercamiento, es altamente peligroso para el estatus quo del colegio y del director del mismo. Por otro lado, cuando se enamora de la hermana de su alumno, Atefeh, se enfrenta de forma inconsciente con el sistema de la protección tradicional del barrio, encarnado en la figura del carnicero, el otro pretendiente de Atefeh. Hekmati no podrá seguir mucho tiempo en este espacio de intervalo, este barrio no tolera las inquietudes intelectuales de un hombre como él.

El viajero (Mosafer, 1974), el primer largometraje de Abbas Kiarostami, construye el mismo espacio educativo basado en un sistema de control y de segregación social. El héroe de la película es Ghasem, el rebelde muchacho obsesionado por el fútbol. Toda la presión de su entorno -desde su madre y el director de la escuela hasta sus propios compañeros de clase- se traducen en un incontrolable deseo de transgredir la ley y viajar a la capital para ver de cerca un partido de futból, de lo cual se ha enterado a través de una revista deportiva. De los pocos signos de la modernidad, en la pequeña ciudad dónde vive él, se observan las fotos de deportistas en el poste de prensa, que en un contraste absoluto con su entorno, le incitan a un potente imaginario de la ciudad. Los mayores expresan su impotencia de poder controlar al niño. El equilibrado sistema tradicional, con la llegada de las imágenes de los futbolistas de la capital se ha quebrantado y han convertido a Ghasem con palabras de Alberto Elena (2002, p. 36) en un "auténtico rebelde, alguien que no se acomoda al sofocante universo que le rodea y que no acepta la derrota". 
En un matiz kiarostamiano, Ghasem proyecta la imagen del padre ${ }^{10}$ en un futbolista al que desea ver de cerca en un partido que se celebra en la capital. El iniciático viaje del niño, en la falta de consejos de algún maestro, va al paralelo de todos los lucidos juegos del autor con el absurdo, hasta convertir a Ghasem en un icónico representante del verdadero orden social de su entorno, el que está cubierto con el barniz de la ideología dominante. Ghasem, cruza su pequeña ciudad, en busca de dinero, y en falta de recursos, lo consigue a través del robo, pillaje y engaño. Llega a la capital, dónde rigen las mismas leyes del dinero, obediencia y control. Su deseo no será cumplido ya que se queda dormido a las afueras del estadio a la espera del inicio del partido, y se levanta momentos después del final del mismo. El soporte de la realidad de Ghasem es su sueño: el duro castigo que le espera al volver a la provincia.

El viajero estaba basado en una antítesis de la estructura de mito de niño sabio, y por tanto parecía una advertencia social a una latente crisis de la identidad en un momento decisivo del contacto social con los iconos de la modernidad. Mientras las políticas de la modernización forzosa habían distanciado la capital a la provincia, el deseo de llegar a la capital -que poseía por su parte un enorme soporte imaginariosignificaba entrar en un camino marcado por el absurdo y caótico sistema de la segregación social. Toda la imaginaria sociedad de bienestar -capaz de producir futból- tenía como soporte una terrorífica distancia entre las clases y sobre todo entre la provincia y la capital. Ghasem, aunque usa todo su ingenio para dejar atrás las barreras reales que le obstaculizan cumplir el deseo, en el fondo lo que consigue es la pesadilla del duro castigo como el principal soporte de su placentera transgresión a la ley del padre. Dicho de otra manera, en un sistema educativo obsesionado más por el control que por la propia enseñanza, el viaje iniciático del menor, le aproximaría a formar parte del mismo sistema por delante del que se ha revelado. Esto antes que nada fue el signo del $\operatorname{caos}^{11}$.

\subsection{Entusiasmo por la victoria}

Kiarostami y Beizai fueron los primeros arquitectos cinematográficos del espacio educativo como signo microcósmico de la institución social, dónde el contacto de los niños con el sistema cristaliza de mejor manera los efectos sociales del Aparato Ideológico de Estado. En este sentido, en estas primeras obras estructuradas sobre el mito del niño, el espacio exterior de los colegios, es el escenario de la decisión del niño errante para poner a prueba su propia individualidad al contacto desnudo con las reglas sociales.

En otra obra de Bahram Beizai Safar (Viaje, 1972) dos niños cruzan una ciudad en busca de los parientes de uno de ellos. La ciudad se convierte en un laberinto

\footnotetext{
${ }^{10}$ Nos referimos al padre biológico, que es o bien ausente en toda la filmografía de Abbas Kiarostami, o bien toma una posición pasiva respecto a las decisiones de su hijo

${ }^{11}$ Si Bastur convierte el caos a cosmos, transgrediendo la ley de los mayores y aprendiendo a la vez del espíritu de su padre, aquí en la ausencia absoluta del padre, Ghasem, entrando en el terreno de lo prohibido, no consigue ni siquiera la falsa imagen del padre (futbolista) y revela lo caótico de su circunstancia
} 
terrorífico que no asegura de ninguna manera la seguridad de los menores. Las reglas de juego, fuera de colegio, van en contraposición absoluta de los mensajes moralizantes del interior del mismo. Este contraste, en un plan simbólico daba indicio de una infraestructura social caótica, a la que la versión oficial intentaba cubrir con un barniz ideológico. El viaje iniciático de los niños, cruzando la ciudad en busca de la verdadera identidad, termina en otro fracaso. Beizai (1992, p.73) indica que los niños de Viaje son herederos de un histórico terror y antes que nada son víctimas de su entorno.

Su única hazaña, es transgredir las leyes al igual del mito de Bastur, pero, como él no consiguen la victoria. El pueblo iraní a lo largo de la historia ha producido -y produce- sus mitos y el ritual que les corresponde "para liberarse de sus terrores" (Beizai, 2009, p.39), pero en Viaje el tratamiento mítico es diferente: el autor fragmenta el mito, para enfrentar a los espectadores con sus propios terrores.

La armónica (Saz Dahani, Amir Naderi, 1973), es otra bella pieza metafórica de estas circunstancias: los juegos infantiles de los niños de la costa sur iraní, se desequilibran con la llegada de una armónica a mano de uno de ellos, la cual se convierte en un instrumento de segregación y control por parte del niño que la posee. El deseo de tocar la armónica por parte de todos los niños da un poder incontrolable a Abdolu, que pide dinero a cambio de unos segundos para tocar el instrumento. Esta situación propaga el germen de delincuencia entre los niños, y sobre todo en Amiru, el niño protagonista quién la extrema pobreza de su familia no le permite disfrutar al nuevo y "moderno" juguete. El final de la película fue otra visión cinematográfica del contexto social de la década de los setenta en Irán: Amiru roba la armónica y la arroja al mar para que no pertenezca a nadie y que él mismo se libere de la tentación de tenerla. Pocos años después, la revolución hizo lo mismo con los signos de la modernización shahiana para tomar el camino contrario al turbulento contexto histórico y restablecer la religión como el nuevo Aparato Ideológico de Estado.

Los niños y el espacio educativo, aparecieron en las primeras obras cinematográficas producidas en Irán en el fervor de la revolución de 1979. En este sentido, hay que apuntar a La escuela que fuimos (Madrese-i ke miraftim, Dariush Mehryui, 1980) como el punto de partida de la presencia de los niños en el cine post-revolucionario. La película fue un perfecto espejo colocado por delante de las circunstancias sociales del Irán revolucionario: en un colegio de chicos, la tiranía e injusticia del coordinador provoca la rebeldía de los estudiantes. El detonante de la revuelta es el ensayo crítico de uno de los niños en el periódico estudiantil y la prohibición del mismo por parte del coordinador tomando la violencia como la única manera de control en el colegio. El artículo criticaba los tratos diferentes a los estudiantes en dos diferentes espacios del colegio: "en el patio delantero todo es aparentemente paz y amabilidad mientras en el patio trasero el trato se convierte en violencia y malos tratos" para coaccionar a los niños aceptando las reglas injustas y el trato discriminatorio. 
El final de la película, tras la revolución de los niños, el vicedirector y sus discípulos tienen que abandonar el colegio, sin embargo como observa lucidamente el crítico Yabbar Azin (1990, p.36) el colegio seguía con dos patios y el director del mismo seguía siendo invisible a la vista del público.

Hamsarayan (El coro, 1982) era la primera reacción de Kiarostami en el periodo revolucionario y basado no obstante sobre su obsesión del destino de los niños fuera del círculo de la protección (Estado-colegio; familia-casa), dónde tienen que decidir por su cuenta para desempeñar los problemas que les causa las estructuras de una sociedad en crisis. Mientras los obreros trabajan en la calle, el abuelo apaga su aparato auditivo para refugiarse en el silencio del ruido de taladradores. Terminando la hora del colegio, las nietas se enfrentan con la puerta cerrada y el abuelo que vive en su mundo silente no oye el sonido del timbre. La película dibuja de la más bella forma posible el enfrentamiento generacional y por tanto el entusiasmo de la victoria: poco a poco, todas las niñas del colegio forman un coro gigante que grita: ¡abre la puerta abuelo!

Este mismo entusiasmo por la victoria de los menores en el ambiente hostil fuera de la casa y el colegio, se repite en la obra de Amir Naderi, Corredor (Davandeh, 1985) que narra la historia de Amir el solitario niño que busca la vida por las calles y por su perseverancia y voluntad puede vencer en una carrera con reglas injustas. Amir, el niño huérfano pronto descubre que su único refugio podrá ser el colegio dónde empieza a aprender el alfabeto. Cuando gana la carrera, recita entusiasmado todo el alfabeto que ha acabado de aprender, desde la primera letra hasta el final, en un solo respiro.

El mismo niño solitario aparece en la obra de Bahram Beizai, Bashu el pequeño extraño (Bashu gharibe-ye kuchak, 1986) que por la circunstancia de la guerra pierde toda su familia y tiene que abandonar su tierra natal y buscar refugio en los campos del norte y en el seno de la familia de Nayi Yan, una mujer campesina que tiene que encargarse por sí sola la casa y sus dos hijos en la ausencia de su marido que se encuentra en el frente. La única manera de comunicación directa entre Bashu y los otros niños de la aldea que le rechazan, es el libro de texto de literatura persa cuyo fragmento recita en una ocasión como la única manera preventiva a la violencia: "Todos somos de la misma tierra, todos somos hijos de Irán”.

\subsection{La proliferación del niño errante}

A pesar de la prolífera presencia del niño en relación con el espacio educativo en el cine iraní en dos décadas setenta y ochenta, hay que reconocer que el punto de inflexión de dicha imagen es la película de Abbas Kiarostami producida en 1987, la que de mejor manera confirma la estructura de niño errante basado en el mito de niño sabio: ¿Dónde está la casa de mi amigo? (Jane-ye dust koyast?). El viaje de Ahmad, el pequeño niño aldeano en busca de la casa de su amigo Mohammadreza en la aldea vecina, para devolverle su cuaderno de deberes que lleva equivocadamente a casa, se convierte en una kiarostamiana odisea heroica, ya que como espectadores hemos sido 
testigos de la angustia de los niños en el sofocante episodio de la revisión de los deberes en la clase, enfrentándose al violento método disciplinario del maestro.

En la casa de Ahmand, la ausencia del padre, nos lleva a la idea de que estamos ante otra lectura inconsciente de Kiarostami al mito de Bastur. Todos los caminos de la comunicación entre los mayores de la casa (la madre y abuela) pronto se clausuran, considerando absurdo el hecho de devolver el cuaderno a un amigo, en vez de escribir los deberes o comprar pan. Ahmad al contrario de Ghasem de El viajero es un alumno aplicado pero el resultado de manifestar su deseo por delante de los mayores tiene el mismo resultado. Al igual que el arquetípico Bastur, no tiene permiso de salir del círculo de protección, marcado por las leyes paternas. No hay manera que Ahmad pueda transmitir a la familia la gravedad de la situación de su amigo Mohammadreza, si mañana vuelve a la clase sin haber hecho los deberes en su propio cuaderno.

Las leyes de la casa, al igual que las reglas del colegio, limitan al niño como un menor obediente. Ahmad se pone manos a la obra por su propia iniciativa y se rebela: sale de la casa rumbo a la casa de su amigo de la cual tan sólo sabe que está en la aldea vecina Poshteh. El camino de Ahmad hacia la casa de su amigo, constituye un poético universo construido por los arquetipos culturales iraníes, que Kiarostami los deconstruye a su manera. La épica de Ahmad no es por sus hazañas exteriores, enfrentando enemigos de la patria -al igual que Bastur- en busca de una huella de su padre, sino consiste en su voluntad de buscar un camino desconocido, en la ausencia absoluta del padre, y a pesar de diferentes obstáculos que le preparan los mayores y entre ellos su propio abuelo. ${ }^{12}$ El final de la épica, está marcada por el fracaso de Ahmad al buscar la casa de su amigo y por una kiarostamiana obsesión a la trasgresión de la ley paterna: Ahmad escribe los deberes de su amigo y así le salva engañando al profesor de la escuela.

El único personaje que en el camino de Ahmad le ayuda, enseñándole el camino, es el viejo ebanista en el que algunos críticos han observado la imagen de un Pir. ${ }^{13}$ El ebanista es el último eslabón de los conservadores de una tradición artística de construir las ventanas de madera, las cuales construye todavía con mucha dificultad, para venderlas luego al corpulento intermediario a un precio injusto. La película termina con la imagen de una flor entre las páginas del libro de Ahmad, el regalo del maestro ebanista, la que para A. Talebineyad (1996, p. 74) expresa su profunda nostalgia hacia un pasado feliz y próspero en un presente marcado por la crisis de

\footnotetext{
12 Véase el brillante diálogo de Ahmad con su abuelo recogido por ELENA Alberto (2002), Abbas Kiarostami, Cátedra, Madrid, Pág. 94.

${ }_{13}$ Pir en la tradición literaria iraní es la figura de maestro espiritual que enseña el camino a los debutantes. Para ver una alusión del mismo relacionado con la película de Kiarostami véase: ISHAGHPOUR, Yousef (2000), Le réel, face et pile: le cinéma d'Abbas Kiarostami, Éditions Farrago, Tours, Pág.71
} 
identidad, y el desprecio hacia la herencia cultural a la que él representa como el último guardián. ${ }^{14}$

Próximo largometraje de Kiarostami Mashgh-e shab (Los deberes, 1989), es un testigo visual al comportamiento inconsciente de los niños en un colegio primario. El tema de la película fue la misma tentación de siempre de un autor que contempla el mecanismo de formación de un irreductible deseo de transgredir la ley por parte de los niños. Como espectadores, a lo largo de las entrevistas que realiza el propio Kiarostami en un colegio primario, nos enfrentamos con las mentiras y contradicciones que dicen los pequeños para salir del paso y como un mecanismo de autodefensa (Elena, 2002, p. 86). La sensación de terror que manifiestan los alumnos, viene de un sistema educativo intransigente -que al igual que la época anterior- da más importancia a propagar su ideología que la misma educación. ${ }^{15}$

Aunque Kiarostami a partir de Los deberes, abandona el espacio educativo, pero la imagen del niño fuera del colegio y de la casa en un absoluto contraste con su familia y su entorno, nunca desaparecen del todo en su filmografía. ${ }^{16}$ Aún así el efecto de la imagen de niño errante duró a lo largo de los años noventa, y tras el reconocimiento internacional de Kiarostami en los festivales europeos, y se convirtió en un signo inconfundible de la originalidad del cine iraní para los cinéfilos internacionales.

De manera que los años noventa fueron testigos de la proliferación de las películas construidas sobre la estructura de lo que aquí llamamos el mito del niño sabio. Diferentes historias se adaptaban a la estructura del mito y poco a poco el protagonismo sale de la exclusividad para los niños. Así pues acogen la opera prima de Yafar Panahi Badkonak-e Sefid (El globo blanco, 1995) y su segunda obra El espejo (Ayeneh, 1998) las historias de dos niñas. Las dos obras de Panahi contribuyen en la madurez del icono objeto de este estudio como unos brillantes ejemplos de los niños del cine iraní de los noventa. El espejo era una reflexión sobre los propios mecanismos de la grabación cinematográfica, a través de la fragmentación narrativa en dos niveles diferentes. En un juego postmoderno, el autor utiliza la imagen del niño errante como una referencia intertextual para poner al espectador ante un juicio moral: mientras seguimos a la niña protagonista del filme, errando en la caótica ciudad en busca de su casa, la película nos da a conocer que todo ha sido una escena de un filme que un equipo está rodando. Aun así la historia no termina aquí, ya que la pequeña actriz se rebela contra las órdenes del equipo, transgrediendo las propias reglas de los

\footnotetext{
${ }^{14}$ De hecho el comportamiento de hombre corpulento, el intermediario de la ventana, marca la tristeza del maestro ebanista. Por tanto, y en un nivel simbólico, estos dos personajes son inseparables a la hora de construir la narrativa microcósmica según el estilo de Kiarostami

1514 La bella estrategia de Kiarostami de cortar el sonido de la película a lo largo de una celebración religiosa en el patio del colegio, es una muestra de ello. Mientras los altavoces, emiten una triste oración religiosa, los niños juegan silenciosamente en las filas y muestran sigilosamente comportamientos contrarios de lo que les exige el profesor responsable.

16 Como ejemplo podemos confrontar el niño de Diez (Dah, 2002) y su último largometraje hasta la actualidad: Copia certificada (Copie Conforme, 2010).
} 
creadores de su personaje y sigue errando en señal de protesta. La película se convierte en un filme dentro del filme y acompañamos al equipo que sigue a su vez a la niña en las calles de la ciudad.

Para finales de los años noventa la fórmula parecía haber sido agotada, y poco a poco el icono de niño se transformaba en adolescentes y jóvenes y sobre todo en las mujeres en el trasfondo urbano. ${ }^{17}$ Aun así los niños no se desaparecieron del todo, sino que en ocasiones, salían como referencia de la iconografía construida anteriormente. Cabe mencionar, la obra de otro director iraní sobre la estructura del mito con gran éxito en la pantalla internacional: Mayid Mayidi, y especialmente su película Baran (Baran, 2001) en la que el mito de niño sabio viste de una adolescente afgana, que encuentra la manera de salir de la crisis económica de su familia en vestirse de chico y trabajar como un jornalero de la construcción.

\section{CONCLUSIONES}

Una tradición de observar a los cines periféricos -y en concreto al cine iraní- desde la perspectiva socio-política, ha dejado un vacío importante de las tradiciones culturales del que estos cines alimentan sus imágenes y conceptos. La literatura, y en concreto la poesía persa ha dejado un brillante patrimonio cultural como una de las fuentes importantes identitarias para un Irán que cruza difíciles momentos de la transición hacia la modernidad. Los mitos antiguos de la cultura persa, reaparecen en el cine y desafortunadamente han quedado a la sombra de los trasluces políticos. En este sentido, los niños errantes constituyen un ejemplo que de alguna manera en la mayoría de las veces han sido descodificados por los criterios de la censura, y por tanto como ejemplos de la escapatoria de los cineastas. Este estudio sin aspirar ser exhaustivo, ha sido un intento de observar dicho fenómeno dentro de su clave cultural, y de aquí en el contexto estructural de los mitos que lo constituye.

El mito de Bastur al igual que el propio Zaratushtra, salva la identidad del pueblo iraní de los invasores con una fuerza e inteligencia sobrenatural propia de los mitos antiguos. Y los niños errantes del cine iraní, en ocasiones son frutos de fragmentación de este mito -como el caso de los filmes de Beizai- y en ocasiones son deconstruidos en un marco moderno en el que indudablemente Kiarostami es el primer maestro. En ambas ocasiones, el mito arquetípico de Bastur es desmitificado y descendido a la realidad cotidiana de un Irán en el transcurso del conflicto con la modernidad. Esta transformación va en oposición de la estructura del mito de niño sabio que transgrede la ley, sale del círculo de la protección familiar-estatal, consigue la meta inaccesible a los mayores- con la ayuda de las enseñanzas del maestro sabio y vuelve al final al círculo anterior y recibe el premio salvando la identidad del pueblo, la que su ausente padre era el guardián. Para los niños errantes de Kiarostami, no hay vuelta

17 Para ver un estudio respecto a la metamorfosis de la imagen de niño errante en la mujer rebelde véase: ZAHEDI, Farshad (2011), “Figuras femeninas en el paisaje urbano: la tetralogía de Dariush Mehryui", Archivo de la Filmoteca, no.67, abril de 2011. Págs. 83-94 
al círculo, ya que la estructura del círculo está en una profunda crisis de identidad, y no puede asegurar la protección prometida.

Por tanto no existe el triunfo final de un niño que busca su propia identidad en un viaje iniciático, y si existe, como es el caso de la obra de Dariush Mehryui, es cuestionado por un juicio que es propio de la modernidad. En este medio, el niño sabio se convierte en el niño errante en busca de su propia identidad más allá del círculo de la protección familiar y de la tutela del Estado. El niño es la única figura que podrá sobrepasar los límites del Aparato Ideológico de Estado, y con su lógica particular, se convierte en un representante del estado ontológico del pueblo iraní.

\section{REFERENCIAS}

Lizadeh, G. (1992). Aks va ayeneh. En Gukasian, Z. Maymue-ye magalat dar moarrefi va nagd-e asar-e Bahram Beizai (pp.129-194). Teherán: Agah.

Amuzegar, Y. \& Tafazzali, A. (1993). Ostureh-ye zendegi-ye Zartosht. Teherán: Avishan y Cheshmeh.

Azin, Y. (1990). Dar hayat-e poshti ham jabari nist. Ettelaat-e haftegi, (2479), 36.

Bahar, M. (1996). Payuheshi dar asatir-e Irán. Teherán: Agah.

Bahar, M. (1998). Az ostureh ta tarij. Teherán: Cheshmeh.

Bahrami, A. (1998). Nemuneha-i az tasvir-e kudak dar adabiat-e Iran. En Pezeshk, M. H.: Tammoli dar honar va sinema-ye kudak va noyavan (pp. 11-33). Teherán: Farabi.

Beizai, B. (1992). Entrevista recogida por Gukasian, Z.: Goftogu ba Bahram

Elena, A. (2002). Abbas Kiarostami. Madrid: Cátedra.

Ferdowsi, A. \& Davis, D. (2004). The Shahnameh: The Persian Book of Kings. Mage Books. Waldorf MD.

Ferdowsi, A. \& Hamidian, S. (2009) Shahnameh. Teherán: Gatreh.

Leví Strauss, C. (1978). Myth and Meaning. Londrés-Nueva York: Routledge.

Tahami Neyad, M. (1992). Ragbar va notfe-haye namadin-e agahi. En Gukasian, Z.: Maymue-ye magalat dar moarrefi va nagd-e asar-e Bahram Beizai (pp. 236-244). Teherán: Agah.

Talebi Neyad, A. (1995). Janeh-i be vosat-e yahan. En Zaven Gukasian: Filmha-ye bargozide-ye sinema-ye Irán dar dahe-ye (pp.67-84). Teherán: Agah. 


\section{Farshad Zahedi}

Farshad Zahedi desde 2008 es doctor en Historia del Cine por la Universidad de Autónoma de Madrid. En la actualidad es Profesor Ayudante Doctor en el Departamento de Periodismo y Comunicación Audiovisual de la Universidad Carlos III de Madrid. Entre sus últimas publicaciones destacan el libro publicado en 2010: 40 Años de cine iraní: el caso de Dariush Mehryui, Fragua, Madrid; y artículos: "Muestras del conflicto heterosexual en el cine iraní" Icono 14, octubre de 2011, año IX, vol. III; y "Figuras femeninas en el paisaje urbano: la tetralogía de Dariush Mehryui", Archivos de la Filmoteca, abril de 2011, núm. 67. 